\title{
Perspectives on Chongming Island, China
}

NANCY Cole

Nancy Cole is a senior in the BCRP program , City and Regional Planning Department, Cal Poly.

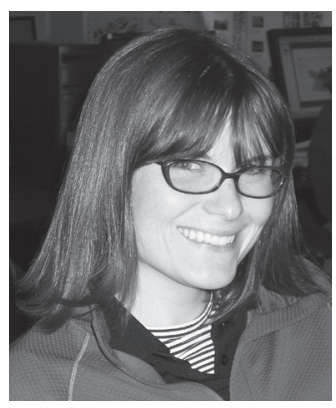

In the Spring of 2008, Nancy Cole and five other Cal Poly students went on a visit to China, sponsored by the National Science Foundation. Their purpose was to investigate the several Chinese and international development projects in Chongming Island. She noted the conflicts between the local ancient culture and globalization, and between the needs of development and the goals of sustainability.

"Seize the great moment, embrace the great future" (Tongji University)

\section{Departure from the Western World}

In June 2008, the National Science Foundation sent six students: four engineers, a social science student and a city-planning student on a study trip to China. The purpose of the trip was to investigate the potential for research projects on an island off the coast of Shanghai, China. Chongming Island has been the focal point of many development projects by the Chinese government and international research institutions. The islland is located at the mouth of the Yangzi River had been in relative isolation from the rapid change that Shanghai and other parts of China had undergone in the last twenty years.

During the twenty first century, the Chongming Island changed rapidly. With change comes many sacrifices to both the people and the environment of the island; however, the people appeared tolerant and excited about some of the changes. With the recent construction of a bridge and tunnel that link Chongming to Shanghai, there is no question that the Island will significantly be urbanized. The challenge is how to create a new model for urban growth that can generate enough water, energy and food to support its inhabitance.

\section{Chongming Place and Pace}

Chongming Island had many yards filled with used windows and doors that were taken from old dwelling units. From afar, the piles of material seemingly looked like garbage, but upon taking a closer look, the piles were finely sorted materials for construction, such as brick, metal, tile, and concrete. The tile and siding was reused in roads and used bricks were re-mortared to construct walls and buildings.

The Chongming Island had an un-harmonized sense of pace. The pedestrians, bicycles, motorbikes, private cars and buses shared one road with varying speeds and directions. Bus travel was a fast paced, wild experience on Chongming. The drivers were like taxi drivers in downtown Shanghai, were they briskly weaved through cars, trucks, bikers and pedestrians as if they had choreographed the entire journey.

\section{The Shift: Lifestyle meets Technology}

People on Chongming Island had seen dramatic shifts in their quality of lifewithin recent years. China provided millions of people with amenities that were not available before. Electronic shops were filled with the latest technology. Appliance shops had modern air conditioners, vacuums, kitchen 
appliances and more. In homes, personal air conditioners were standard, and energy conservation was common practice. Task lighting, localized cooling, and use of day lighting demonstrated an ethic of energy saving.

China had instituted its own energy rating system, like EnergyStar in the United States, which rates the efficiency of appliances. Customers read the products energy facts, just like they read nutrition facts on a package of food. Western-style driers, while timeefficient, were seen as energy wasting and too harsh on clothing.

There were technologies on the island that had become so standard that most people had access to these amenities. Everyone from the taxi driver to the local farmers had cell phones. This type of technology provided people of the island the ability to communicate

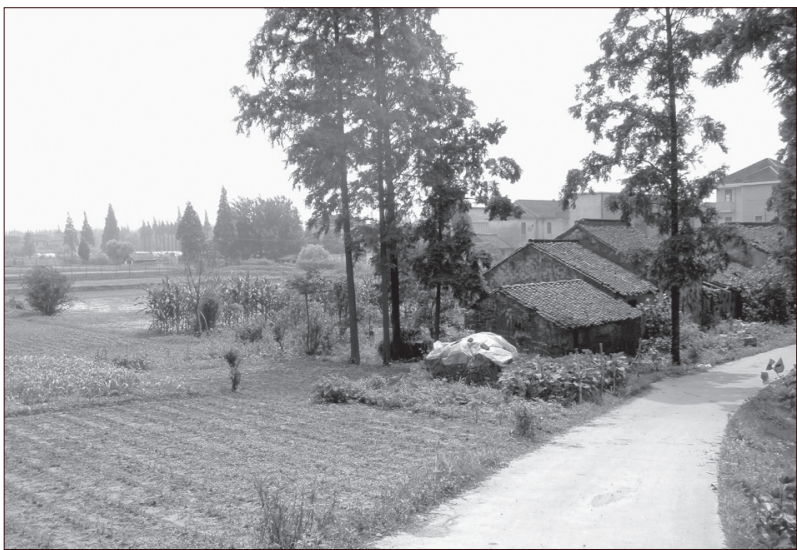

Figure 1

Chongming Island's landscape puts to use all available land for agricultural purpose. solar hot water tanks had become popular within the last ten years When asking the local distributor why this technology took off so quickly, the response was because of the very short payback period. People saw the benefits in the short term.

We visited a pilot biogas facility that was fueled by pig manure. A community of 20 used the gas for cooking. While the facility was fully operational, the community said the government found it as an economic waste because it was not as affordable. It seemed like with every project, however environmentally beneficial it might be, it had to have a short-term payback to be widely distributed.

\section{The Scent of Progress}

The quality of the air is a powerful indicator of the quality of an environment. Fresh, crisp air reminds us that natural systems are in balance. China is often denoted for its toxic air: the industry, the coal plants, the city smells and wastewater issues. However, Chongming is a unique place in China. It is a place where the thick gray haze of the big city is cut by the purifying effects of lush planted forests and carbon-capturing wetlands. The island is clearly a sanctuary from the same pressures that Shanghai and other industrializing cities have faced. But many indicators show signs that Chongming may very well fall into the same trappings that other cities have fallen into.

On the first trips to the island, we observed many notable land uses that might have posed significant conflicts with sustaining and retaining the quality of the environment and preserving the customs that exist on the island.

We passed places on the island that were completely destroyed and abandoned. The future was left unknown. The demolition of homes and displacement of people were a common practice on the island, according to Gong, a Tongji University student from Shanghai and a former resident of Chongming. Gong suggested that the future of the Chongming people was extremely uncertain because their living patterns had been disturbed. Eminent domain was a major issue on the island. Whole communities had been moved to make way for the new bridges, eco-tourist parks and highrise developments.

A farming community of about 900 was moved to a nearby apartment complex. We visited their abandoned homes. Rubble and empty shells were the only indication of the community that once was. And for the first time, I understood where all those old doors and windows were coming from. 
These building materials were ravishes of homes and lives that used to exist on the island. These lives would be replaced with new lives that come with all the twenty-first century standards that humanity craves.

The farming community had been moved to an 8,000-unit complex with all the modern amenities of any western-styled development; complete with a gym, childcare facility, a market, hotel and hospital. We were generously offered entry into a family of five households. They gave us a tour of their two-bedroom apartment, and offered us watermelon. This ultra-modern apartment, decorated in an IKEA-style was completed with sleek furnishings and China- chic color palette. I thought to myself, what a great apartment for these people! They seemed so content with life. They explained that the government provided them with their apartment free of rent and two additional apartments to generate income. I realized that these people had no longer any connection to the land. They were no longer farmers; their history was erased, what was left was the remnant's of their old homes, which would be used as paving for another road.

The balance between land rights and civic duty was just as important as the balance between modernizing and preserving cultures. Whether or not these people were able to maintain their identity amidst this process of urbanization had yet to be determined. I thought back to the 1950's post-World War II era in the United States. During this time, people had such an extreme optimism and sense of opportunity. Now, I think how the 1950's created both physical and social challenges that we face today. I do not know what the future holds for these people, but I can only hope for the best.

Prior to coming to China, my perception was that the people would be extremely insecure and dissatisfied with the changes that are occurring on the island. My concerns were validated by Gong's perceptions but no one that I encountered who lived on the island seemed apprehensive or unwilling to confront change. Opportunity and development seemed intrinsically linked in China. They perceived China's steps toward change had been moving in a positive direction.

Some of my lasting impressions of China wereimages of Pudong, the east side of Shanghai, filled with skyscrapers and cranes. The streets wererelatively barren compared to the amount of construction that is going on. I envisioned Pudong 20 years prior and saw Chongming Island, filled with agricultural fields and farmers making a living selling food at local markets. The life on Chongming

Figure 2 Streets are riddled with garbage and older buildings lack proper maintenance.

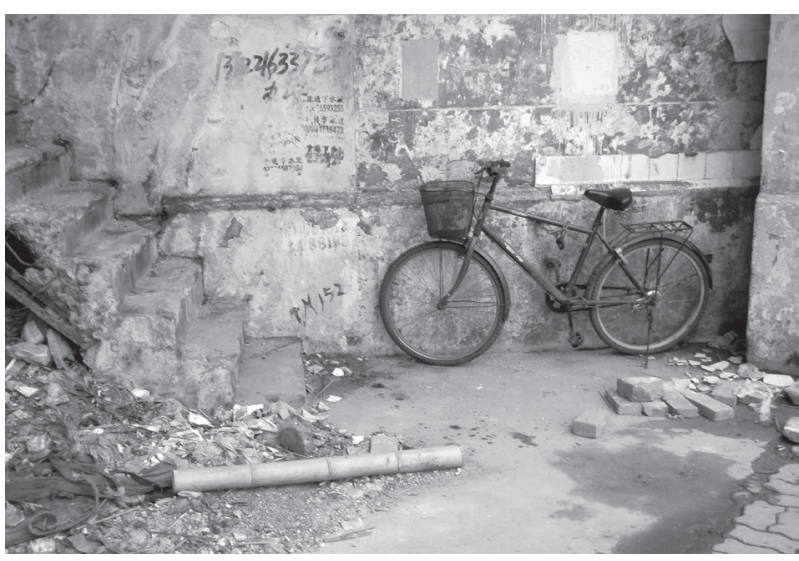
Island was highly reminiscent of what I envisioned downtown Shanghai before the big boom.

The pressures on Chongming Island were observed in the agricultural sector. The inhabitant's lifestyles were heavily influenced by a deep connection to the land. All the land on Chongming was extremely well utilized, with food crops grown on almost every open piece of available land. People grew food on hillsides, at road edges, next to businesses, and in playgrounds. It seemed like most people have some form of garden, even people in the high-rises utilized every available piece of land for cultivating food.

\section{Food and Livelihoods}

Urban children from Shanghai were brought to the island to learn the value of farmlands, but were not shown the value of preserving and cultivating land in their own living space. These toolsets are not practical unless applied back to the urban setting.

In Chongming, Agriculturists were divided up into two major categories: 
those that a were farming for subsistence and those that had larger agricultural operations for foreign or domestic markets. The commercial farming operations use domestic and migrant laborers from other provinces, similar to the migrant laborers in the US coming from Mexico. The smallscale farmers maintain a family operation. They may sell to foreign market, but have preserved some of their family traditions.

For those that could afford it, farmers switched to organic production because they received four times as much for their produce. Commercial organic farmers often switched to mechanized farming because of the increase in revenue.

Tractors were not commonly used, and on the entire visit, only one or two

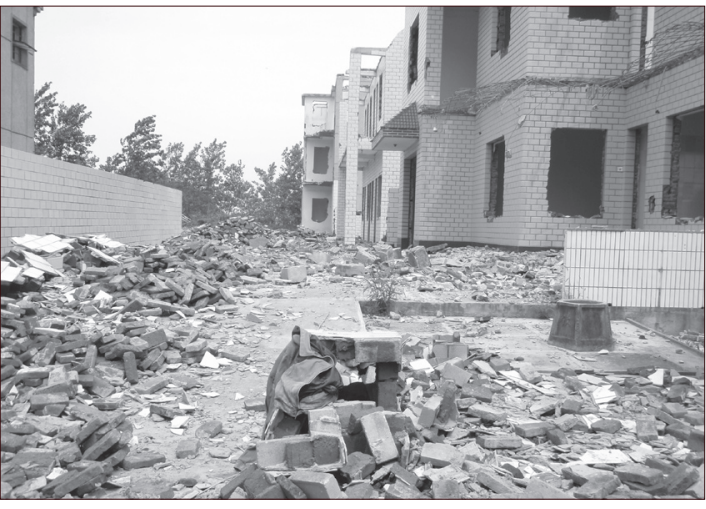
tractors were spotted in use. The shifting trends toward mechanization were creating new jobs for people on the island. While the patterns of growing and tending the land had changed, the seasonal practices, such as rotation of the crops or applying natural fertilizers are still common practice.

Chongming had strict rules about not over-farming and over-fishing the island. During the summer, no boats were allowed out of the canal to catch fish because they understand that would destroy the natural regeneration period for the fish. The canals were left open for the importing and exporting of goods and raw materials, such as the exportation of rice and the importation of bottled drinks.

The evolution of agricultural patterns on Chongming applied traditional farming practices to changing circumstances. A local herb farmer and his son said his family had utilized the same practices for generations. He made it clear that the surrounding land development increased affluence and access to mobility and would not alter his farming practices. The farmer had also been selling his product on the domestic and international market. In contrast, an organic large-scale farmer had significantly altered his practices because of the increase demand and desire to output a higher yield.

As traditional patterns of farming are becoming less prevalent alongside the overall decrease in domestic farming caused by urbanization on the island,, there is a growing interest in preserving skills and maintaining an appreciation for the land.

\section{Final Thoughts}

To be truly sustainable, how can a place sweep a whole history and culture under the proverbial rug? The ecotourism model emphasizes not giving handouts, but meaningful opportunities to the people that inhabit the area. Chongming is not yet modern enough to hide the real problems it has related

Figure 3

Communities are moved, homes disassembled, and lives altered by government-initiated evictions.
Figure 4

Piles of sorted construction materials are carefully organized for reuse. to labor issues and human rights issues. One day soon, it will be modern enough to hide its own history.

China faces two realities: a rich historical tradition amidst the pressures of its transforming world. The legendary speed of development have forever changed the way humankind perceives pace, place, and lifestyle.

The vernacular constructs-influenced by Westernization, globalization and an emergent open economy-have rapidly modernizing. Upgrading amenities have forever altering living patterns through the built environment. But what we cannot always see, what we never hear, and what I still have yet to understand is the process of creating this shifting world.

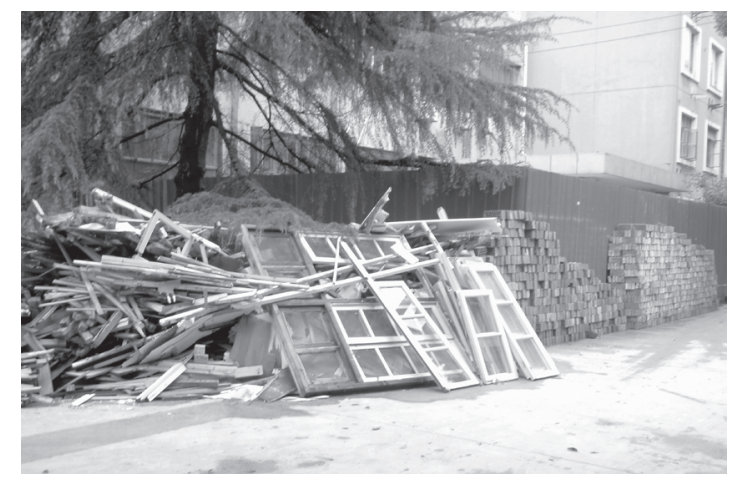

